\title{
REPRESENTAÇ̃̃ES SOCIAIS DE MULHERES SOBRE AAMAMENTAÇÃO: TESTE DE ASSOCIAÇÃO LIVRE DE IDÉIAS ACERCA DA INTERRUPÇÃO PRECOCE DO ALEITAMENTO MATERNO EXCLUSIVOa
}

\author{
Social Representations of Women on Breastfeeding: Free Association of Ideas \\ Test About the Early Interruption of the Exclusive Maternal Breastfeeding \\ Representaciones Sociales de Muj eres Sobre el Amamantamiento: Prueba de Asociación \\ Libre de Ideas Acerca de la Interrupción Precoz del Amamantamiento Materno Exclusivo
}

Cácia Mônica Osório

Ana Beatriz Azevedo Queiroz

\begin{abstract}
Resumo
A interrupção prematura do aleitamento materno exclusivo (AME) constitui um problema com características biológicas, psicológicas e socioculturais. Este trabalho visa descrever as representações sociais da amamentação para mulheres que interromperam precocemente o AME. Foram entrevistadas 30 mulheres ( 15 trabalhavam no lar - Ntr, 15 trabalhavam fora - Tr) em aleitamento misto atendidas no Programa Saúde da Família do município de Resende (RJ). Os dados foram coletados de agosto a outubro de 2005 através do Teste de Associação Livre de Idéias, visando emergir associações relativas às palavras exploradas ao nível dos estereótipos sociais, seguido da análise de conteúdo de Bardin. Os dados mostraram elevada freqüência da categoria "prazer, amor e carinho", demonstrando o reconhecimento da importância do aleitamento e do leite humano. "Saúde do bebê" teve maior expressividade no grupo NTr, sugerindo que essas mulheres ancoraram a amamentação no processo saúde-doença. Concluiu-se que as mulheres reconhecem a importância de amamentar, mas não de sua exclusividade até o sexto mês.
\end{abstract}

Palavras-chave: Amamentação. Aleitamento Materno. Desmame Precoce. Pesquisa Qualitativa.

\begin{abstract}
The early interruption of exclusive breastfeeding (EB) constitutes a problem with biological, psychological and sociocultural characteristics. This paper aims to describe the social representations of women who have early weaned EB. We have interviewed 30 women ( 15 were housewives HM, 15 were working mothers - WM) in mixed assited nursering in the Family Health Program in the city of Resende (RJ). From August to September 2005, we have collected data through a Free Association of Ideas test, aiming to emerge associations related to the words exploited at the level of social stereotypes, which was followed by the Bardin's content analyses. The data have shown high frequency of the category "pleasure, love and affection", showing the recognition of the importance of breastfeeding and of human milk. "Baby's health" has been more expressive in the HM group, suggesting that these women anchored breastfeeding in the health-sickness process. In conclusion, our women recognize the importance of breastfeeding but not its exclusiveness up to the sixth month of age.
\end{abstract}

Keywords: Breastfeeding. Maternal Nursering. Early Weaning. Qualitative Research.

\section{Resumen}

La interrupción prematura del amamantar materno exclusivo (AME) constituye un problema con características biológicas, psicológicas y socioculturales. El presente trabajo pretende describir las representaciones sociales sobre el amamantar por mujeres que interrumpen de manera precoz el AME. Entrevistamos 30 mujeres ( 15 trabajaban en hogar - Ntr, 15 trabajaban fuera de la casa - $\mathrm{Tr}$ ) en amamantar mezclado asistidas en el PSF del municipio de Resende (RJ). Los datos fueron coleccionados de agosto a septiembre de 2005, por medio de una Prueba de Libre Asociación de Ideas, pretendiendo resultar asociaciones relativas a las palabras exploradas al nivel de los estereotipos sociales, al que se siguió el análisis del contenido de Bardin. Los datos apuntaron señales de elevada frecuencia de categoría "placer, amor y cariño", que demuestran el reconocimiento de la importancia del amamantar materno y de la leche humana. "Salud del bebé" tuvo mayor expresividad en el grupo NTr, sugerido que esas mujeres anclaron el amamantar en el proceso saludenfermedad. Concluyese que las mujeres reconocen la importancia de amamantar, pero no de su exclusivismo hasta el sexto mes de vida.

Palabras clave: Amamantación. Amamantar Materno. Destete Precoz. Pesquisa Calitativa. 


\section{INTRODUÇÃO}

A interrupção prematura do aleitamento materno exclusivo (AME) é, ainda hoje, um problema de saúde que necessita de intervenção e apoio público. Dados da última pesquisa realizada pelo Ministério da Saúde em 1999, que avaliou a prevalência do AME por idade, mostrou que, aos 30 dias de vida, apenas $53,1 \%$ das crianças brasileiras continuavam sendo alimentadas exclusivamente com leite materno. No quarto mês, a proporção de crianças em AME correspondia a 18\% do total, declinando para $8 \%$ no final do sexto mês ${ }^{1}$. Este dado nos mostra que existe um grande entrave na manutenção do $\mathrm{AME}$, pois a introdução precoce de outros alimentos se inicia habitualmente no período que se segue à alta hospitalar da nutriz, ou seja, quando retornam mãe e filho para o seu domicílio. Uma vez de volta ao seu contexto social, a mulher sofre interferências na sua forma de pensar e agir com relação ao aleitamento. Para revertermos as causas da interrupção do AME, é preciso compreendê-las dentro de um contexto sócio-econômicocultural no qual a mulher está inserida. Jodelet relata que os sujeitos compreendem e interpretam diferente situações na qual se encontram, não se comportando de maneira semelhante diante de um procedimento que permanece idêntico, eles se organizam de acordo com a sua representação $0^{2}$. Réa sustenta que o desmame é um processo social e, como tal, não deve ser visto como fato isolado, unicausal, pontual, exceto em raríssimas exceções. Sob este aspecto, o comportamento da mãe nutriz pode ser influenciado pelo pensamento coletivo, ou seja, as representações se tornam capazes de interferir no comportamento dessas mulheres interna e mentalmente ${ }^{3}$. Moscovici afirma que as representações sociais (RS) podem influenciar o comportamento do indivíduo participante de uma coletividade. Desse modo, o próprio coletivo penetra como fator determinante, dentro do pensamento individual ${ }^{4}$. Considerando a interrupção precoce do AME como um problema de cunho psicossocial com características biológicas, psicológicas e socioculturais, que precisam ser estudadas, esta investigação teve como objetivo descrever as representações sociais sobre amamentação em mulheres que interromperam precocemente o AME.

Pretendemos que este estudo suscite discussões e reflexões acerca de aspectos do cotidiano assistencial de equipe de enfermagem que lida com a saúde da mulher, abrindo novas perspectivas para 0 atendimento à gestante, à puérpera e à nutriz no que se refere às questões da amamentação, visando possibilitar uma assistência mais pertinente e humanizada voltada para a realidade das mulheres. Esperamos, ainda, que esta investigação permita, com seus dados, auxiliar a outros profissionais de saúde que atuem nesta área e fornecer subsídios para os gestores do sistema de saúde na busca de metas de assistência pré-natal, pós-natal e de puericultura no que tange à prevenção da interrupção precoce do AME.

\section{METODOLOGIA}

Trata de pesquisa descritiva com abordagem qualitativa. 0 cenário para a investigação foram duas unidades de Programa
Saúde da Família (PSF) do município de Resende (RJ). 0 estudo teve como sujeitos 30 mulheres que fizeram pré-natal nas referidas unidades, com filhos de zero a seis meses de vida que interromperam o AME. Os sujeitos foram classificados em dois grupos: Ntr (grupo de mulheres que trabalham somente no lar) e $\operatorname{Tr}$ (mulheres que trabalham fora), sendo 15 representantes de cada segmento. Foram excluídas da amostra mães que tiveram o aleitamento contra-indicado ou impossibilitado por razões de ordem médica. Como procedimento de coleta de dados, inicialmente utilizamos um questionário com o propósito de traçar o perfil das entrevistadas. A seguir, foi aplicado um Teste de Associação Livre de Idéias (ALI), o qual visava fazer emergir dessas mães associações livres relativas às palavras exploradas ao nível dos estereótipos sociais espontaneamente partilhados pelos indivíduos de cada grupo social. A questão que orientou o uso dessa técnica foi: Diga o que the vem à mente quando se fala em: amamentação, dar só peito, tirar do peito e leite do peito. A partir daí, as mulheres associaram frases e explicaram as idéias associadas aos termos indutores. Ressaltamos que esses termos foram perguntados separadamente.

Para analisar os dados, as fitas magnéticas com as falas da ALI foram transcritas, identificando a seguir ligações das palavras induzidas entre si, as quais foram agrupadas em categorias, quer por semelhança, diferença ou relação de implicações diversas com o tema representado. As diversas categorias, com seu respectivo termo indutor e sua freqüência observada em cada grupo (Ntr e Tr), foram organizadas em tabelas, para melhor visualização. Ao material coletado procedeu-se a análise de conteúdo temática de Bardin, adequada ao estudo das motivações, atitudes, valores, crenças e tendências. Esse método permite explorar as relações que os indivíduos mantêm com os objetos, pessoas e fenômenos, relações estas que remetem para as $\mathrm{RS}^{5}$. Queiroz ${ }^{6}$ ressalta que para compreender o fenômeno, é necessário procurar captar não só 0 discurso, mas também a situação que define o indivíduo que o produz.

Em conformidade com a Resolução n $196 / 96$ sobre pesquisa envolvendo seres humanos, do Conselho Nacional de Saúde, foram garantidos o sigilo e anonimato às entrevistadas. Para tanto, a identificação das mulheres participantes foi representada pela letra M seguida de um numeral. Sua adesão foi estritamente voluntária. Com essa finalidade, foi solicitada às mesmas a leitura, e, no caso de aceitação, a assinatura de Termo de Consentimento Livre e Esclarecido. Ainda com relação aos cuidados éticos de pesquisa, 0 projeto desta pesquisa foi enviado juntamente com uma solicitação de parecer ao Comitê de Ética da Escola de Enfermagem Anna Nery - Hospital Escola São Francisco de Assis/Universidade Federal do Rio de Janeiro, que autorizou o início do procedimento de coleta de dados (Protocolo $n^{0}$ 043/ 05).

\section{RESULTADOS E DISCUSSÃO}

\section{Caracterização dos suj eitos do estudo}

Para melhor visualização das diferenças dos dois grupos estudados foi elaborado a Tabela 1, que mostra as principais características das participantes do estudo. 


\section{Tabela 1:}

Características das participantes do estudo. Resende - RJ, 2005

\begin{tabular}{l|c|c}
\hline $\begin{array}{c}\text { Características das } \\
\text { participantes do estudo }\end{array}$ & $\begin{array}{c}\text { Mulheres que não } \\
\text { trabalham fora } \\
\text { Ntr }(\mathbf{n}=15)\end{array}$ & $\begin{array}{c}\text { Mulheres que } \\
\text { trabalham fora } \\
\operatorname{Tr}(\boldsymbol{n}=15)\end{array}$ \\
\hline Idade média (anos)* & $24,5 \pm 4,3$ & $30,4 \pm 7,3$ \\
Moram com companheiro (\%) & $100 \%$ & $80 \%$ \\
Escolaridade (anos)* & $8,3 \pm 2,3$ & $8,8 \pm 3,1$ \\
$\begin{array}{l}\text { Renda familiar per capita, } \\
\text { em reais }\end{array}$ & $128,6 \pm 64,5$ & $181,4 \pm$ \\
Via de parto cesárea (\%) & $60 \%$ & $60 \%$ \\
Idade de término de & $2,5 \pm 1,6$ & $3,3 \pm 1,3$ \\
AME (meses completos)* & \multicolumn{2}{|l}{${ }^{*}$ média \pm desvio-padrão }
\end{tabular}

Foi observado que a idade média foi menor no grupo Ntr em relação ao grupo $\operatorname{Tr}(24,5$ versus 30,4 anos, respectivamente). Todas as mulheres do grupo Ntr e a maioria $(80 \%)$ das mulheres do grupo Tr moravam com companheiro. 0 grau médio de escolaridade diferiu pouco entre as mulheres $(8,3$ versus 8,8 , respectivamente), enquanto que a renda familiar per capita média foi quase $50 \%$ superior no grupo Tr em relação ao Ntr ( Ntr de 128,6 reais; Tr de 181,4 reais). 0 percentual de parto cesáreo foi de $60 \%$ em ambos os grupos. A idade média de término do AME foi menor no grupo Ntr em relação ao grupo $\operatorname{Tr}$ (2,5 meses versus 3,3 meses, respectivamente).

\section{Descobrindo as RS sobre a amamentação: uma análise através da ALI}

Este tópico apresenta uma análise das respostas obtidas através de estímulo induzido pelas palavras ou expressões "amamentação", "dar só peito", "tirar do peito" e "leite do peito". Cabe ressaltar que as participantes mencionaram frases e explicaram as idéias associadas às palavras indutoras.

\section{Amamentação}

As respostas das mulheres obtidas através do termo indutor "amamentação" foram agrupadas em 3 categorias conforme a Tabela 2.

\section{Tabela 2:}

Distribuição por percentual das associações relativas à palavra amamentação. Resende - RJ, 2005.

\begin{tabular}{|c|c|c|c|c|c|c|}
\hline \multirow[t]{2}{*}{ CATEGORIAS } & \multicolumn{2}{|c|}{ Total } & \multicolumn{2}{|c|}{$\begin{array}{c}\text { Grupo que } \\
\text { não trabalha } \\
\text { (Ntr) } n=15\end{array}$} & \multicolumn{2}{|c|}{$\begin{array}{l}\text { Grupo que } \\
\text { trabalha fora } \\
(T r) n=15\end{array}$} \\
\hline & $f$ & $f \%$ & $f$ & $f \%$ & $f$ & $f \%$ \\
\hline Prazer, amor, carinho & 31 & $72 \%$ & 17 & $63 \%$ & 14 & $87 \%$ \\
\hline Saúde do bebê & 08 & $19 \%$ & 06 & $22 \%$ & 02 & $13 \%$ \\
\hline $\begin{array}{l}\text { Não gosta, obrigação, } \\
\text { paciência e dependência }\end{array}$ & 04 & $9 \%$ & 04 & $15 \%$ & 00 & $00 \%$ \\
\hline Total de evocações & 43 & $100 \%$ & 27 & $100 \%$ & 16 & $100 \%$ \\
\hline
\end{tabular}

Para a palavra indutora "AMAMENTAÇÃO", a categoria mais freqüente foi "prazer, amor e carinho", com $72 \%$ do total de evocações. A esta, seguiu-se "saúde do bebê com 19\% e, por último, "não gosta, obrigação, paciência e dependência" que apresentou um percentual de $9 \%$. Quando a variável trabalho fora do lar foi analisada, o grupo Ntr apresentou um total de 27 evocações, enquanto que no grupo $\operatorname{Tr}$ o total foi de 16 evocações. No que se refere à categoria "prazer, amor e carinho", observa-se a freqüência deste sentimento tanto no grupo Ntr quanto no grupo Tr, sendo porém um pouco mais freqüente no grupo de mulheres Ntr (17).

Spíndola ${ }^{7}$ refere que a relação da mãe com seu filho é, em geral, um sentimento presente na mulher porque a convivência diária, desde a concepção, cria vínculos significativos que os aproximam. Por conseguinte, passam a ser uma só pessoa em termos afetivos, numa relação de amor e cumplicidade. Esta categoria pode ser ilustrada pelas falas das mulheres entrevistadas nos dois grupos, apresentadas a seguir.

É bom porque ela sente pertinho da gente. Criança gosta de ficar no peito da mãe ( $\mathrm{M}^{1}$ - grupo $\mathrm{Tr}$ ).

Quando a gente está amamentando, a gente tá ali, brincando com ela, é uma coisa muito legal porque a gente faz carinho. ( $\mathrm{M}^{2}$ - grupo Ntr)

Nesta categoria verifica-se o vínculo existente nas falas das entrevistadas. $\mathrm{Na}$ amamentação, o contato físico é maior e proporciona à mãe e ao bebê um momento de proximidade diária. Chodorow ${ }^{8}$ corrobora que as mulheres maternam, e não apenas geram filhos. Assumem responsabilidade pelo cuidado da criança, dedicando-lhe mais tempo, e mantém os primeiros laços emocionais com os bebês. Isso pode ser percebido pelo ato da amamentação. Badinter ${ }^{9}$ sustenta que 0 aleitamento materno é a primeira prova de amor da mãe pelo filho, pois engendra sentimentos de prazer, físicos e morais. A mãe é a principal dispensadora de amor para o recém-nascido e o bebê.

Outra categoria que emergiu quanto à representação da amamentação foi "saúde do bebê". Tais mulheres referem que amamentar significa promover a saúde para o bebê principalmente por evitar doenças. 0 grupo Ntr apresentou uma evocação superior ao grupo $\operatorname{Tr}(22 \%$ versus $13 \%$, respectivamente). A seguir, são apresentadas algumas falas:

Eu sei que é saudável, faz bem para o neném porque protege. Ela não fica doente ( $\mathrm{M}^{3}$ - grupo Ntr).

É um remédio, principalmente o primeiro leite, né, que é o colostro, que previne ele das doenças ( $\mathrm{M}^{4}$ - grupo Ntr).

Percebe-se nesta categoria que as vantagens mais difundidas sobre o aleitamento materno se referem à saúde da criança. É possível perceber no conteúdo das entrevistas que as mulheres que não trabalham fora ancoram a amamentação no processo saúde-doença, ou seja, a amamentação é importante porque o leite materno representa "remédio" e evita doenças na criança. Essas mulheres ancoram a amamentação no senso comum de que saúde é simplesmente ausência de doença e objetivam o leite humano como um veículo protetor de doenças. 
As mães compartilham o conhecimento teórico do aleitamento materno em um conhecimento típico do universo reificado.

No processo de objetivação, a intervenção social ocorre no ajustamento e na forma de conhecimento relativos ao objeto de transformação, articulando-se a uma característica do pensamento social, a propriedade de tornar concreto o abstrato, de materializar a palavra a partir de uma imagem mental ${ }^{4}$. Os depoimentos das entrevistas revelam o que elas pensam e sabem sobre os benefícios da amamentação para o bebê. Pode-se inferir que esse conhecimento é adquirido principalmente através dos profissionais de saúde durante 0 pré-natal, na maternidade e no pós-parto. Elas referem que esse benefício é abordado constantemente no atendimento de saúde, seja nos grupos educativos ou nas consultas. Isto, se evidencia nas seguintes falas:

Eu soube sobre amamentação através dos agentes comunitários de saúde ( $\mathrm{M}^{5}$ - grupo Ntr).

Eu fiquei sabendo no pré-natal , tive bastante palestra ( $\mathrm{M}^{6}$ - grupo $\left.\mathrm{Tr}\right)$.

No entanto, emergiu uma categoria que expressou sentimentos negativos com relação à amamentação que foi a categoria "não gosta, obrigação, paciência e dependência". Ela surgiu apenas no grupo Ntr, com uma freqüência de $15 \%$. No grupo Tr, esta categoria não foi evocada nenhuma vez, como podemos verificar na Tabela 2. A seguir apresentam-se algumas expressões:

Eu não gosto de dar mamar no peito. Mas já que é o melhor dou assim mesmo. ( $\mathrm{M}^{7}$ - grupo Ntr).

Acho que a gente tem que ter muita paciência para dar o peito. ( $\mathrm{M}^{3}$ - grupo Ntr).

È verificado nessas falas que as mulheres deste grupo (Ntr) relevam que a amamentação é um processo fatigante, principalmente pelo fato de o bebê mamar a toda hora. As tarefas do lar e os cuidados com os filhos, associados muitas vezes à falta de apoio, fazem com que algumas mulheres sintam-se sobrecarregadas na prática do AME, a qual requer tempo, disponibilidade e, sobretudo, dedicação integral. Tais dificuldades precisam ser discutidas com a mulher desde a descoberta da gravidez ou até mesmo no planejamento familiar.

Spíndola ${ }^{7}$ aborda que as mulheres assumem mais de um papel ao serem mulheres-mães e trabalhadoras do lar. Estes diversos papéis por ela assumidos entram em conflito, prevalecendo ora um, ora outro, obrigando-a a conciliá-los. A partir daí, surgem momentos de dúvidas, questionamentos e muitas solicitações. Pode-se observar nesta categoria que estas mulheres, embora não ponham em dúvida a importância do aleitamento, sentem-se sobrecarregadas física e emocionalmente, o que sem dúvida torna-se um fator gerador da interrupção do AME.

\section{Dar só peito}

Quando se perguntou as mulheres sobre o termo indutor "dar só peito", várias evocações emergiram, as quais foram agrupadas em quatro categorias, conforme a Tabela 3.

\section{Tabela 3:}

Distribuição das associações à palavra dar só peito.

Resende - RJ, 2005.

\begin{tabular}{|c|c|c|c|c|c|c|}
\hline \multirow[t]{2}{*}{ CATEGORIAS } & \multicolumn{2}{|c|}{ Total } & \multicolumn{2}{|c|}{$\begin{array}{c}\text { Grupo que } \\
\text { não trabalha } \\
\text { (Ntr) } n=15\end{array}$} & \multicolumn{2}{|c|}{$\begin{array}{l}\text { Grupo que } \\
\text { trabalha fora } \\
(T r) n=15\end{array}$} \\
\hline & $f$ & $f \%$ & $f$ & $f \%$ & $f$ & $f \%$ \\
\hline $\begin{array}{l}\text { Prende muito tempo, } \\
\text { difícil dar toda hora, } \\
\text { cansativo }\end{array}$ & 24 & $59 \%$ & 13 & $87 \%$ & 11 & $42 \%$ \\
\hline $\begin{array}{l}\text { Interrupção devida ao } \\
\text { trabalho }\end{array}$ & 10 & $24 \%$ & 00 & $00 \%$ & 10 & $39 \%$ \\
\hline Provoca dor & 05 & $12 \%$ & 00 & $00 \%$ & 05 & $19 \%$ \\
\hline $\begin{array}{l}\text { Não satisfaz, não } \\
\text { sustenta, bebê chora muito }\end{array}$ & 02 & $5 \%$ & 02 & $13 \%$ & 00 & $00 \%$ \\
\hline Total de evocações & 41 & $100 \%$ & 15 & $100 \%$ & 26 & $100 \%$ \\
\hline
\end{tabular}

Quando a expressão "dar só o peito" foi apresentada às mulheres, a categoria mais freqüente foi "prende muito tempo, difícil dar toda hora, cansativo" (59\%), seguida pela categoria "interrupção devido ao trabalho"(24\%),"provoca dor" (12\%) e, por último, " não satisfaz, não sustenta, bebê chora muito" (5\%).

Analisadas essas categorias em relação aos grupos Ntr e Tr, foram verificadas diferenças significativas. No entanto, a categoria "prende muito tempo, difícil dar toda hora, cansativo" emergiu em ambos os grupos, porém com uma freqüência bastante significativa no grupo Ntr (87\%), que demonstra que o ato de amamentar exclusivamente é uma prática que demanda tempo, motivo pelo qual as mães ficam muito cansadas.

Fatores como o próprio estado de saúde física e mental da mulher, sua carga de trabalho doméstico sem apoio, como foi demonstrado na categoria anterior com relação ao termo indutor amamentação, e, por outro lado, a possibilidade de contar com substitutos adequados, quando é necessário se afastar do cuidado direto da criança, são fatores que interferem na prática da amamentação exclusiva desse grupo em especial, como é verificado nos depoimentos abaixo:

O meu dia é bem tumultuado, agitado, faço tudo sozinha e cuido dos outros filhos também ( $\mathrm{M}^{8}$ - grupo $\mathrm{Ntr}$ ).

Eu fico muito cansada durante o dia, por isso que de noite dei mamadeira para eu conseguir dormi. ( $\mathrm{M}^{7}$ - grupo Ntr).

No entanto, esta categoria também emergiu na fala das mulheres do grupo oposto ( $\mathrm{Tr}$ ), com $42 \%$. Além dos fatores citados pelo grupo Ntr para alegar o cansaço, a dificuldade em dar o peito a todo instante tem a sobrecarga adicional da dupla ou tripla jornada de trabalho da mulher, tanto no espaço público como no privado. Algumas falas das mulheres apresentadas a seguir mostram esta questão:

É muito cansativo ter que cuidar dela e trabalhar. 0 meu trabalho é muito cansativo, trabalho em uma lanchonete à noite ( $\mathrm{M}^{9}$ - grupo $\mathrm{Tr}$ ).

Eu gosto de dar mamar para ele, mas tem vez que irrita porque às vezes quero fazer alguma coisa ( $\mathrm{M}^{10}$ - grupo $\mathrm{Tr}$ ). 
Uma outra categoria que emergiu com uma freqüência de $24 \%$ no grupo $\operatorname{Tr}$ foi a "interrupção devido ao trabalho". A volta ao trabalho foi um fator que contribuiu para a introdução de outros alimentos. 0 trabalho das mulheres fora de casa tem sido apontado como uma das razões para a nãoamamentação e o desmame precoce. 0 retorno ao trabalho também está mais relacionado à falta de apoio social e ao descumprimento das leis trabalhistas ${ }^{3}$.

Se eu não tivesse que trabalhar não tiraria ela do peito de jeito nenhum. Até 4 meses era só peito ( $\mathrm{M}^{11}$ - grupo $\mathrm{Tr}$ ).

Se eu não voltasse a trabalhar eu não daria a mamadeira para ela, realmente não ( $\mathrm{M}^{12}$ - grupo $\left.\mathrm{Tr}\right)$.

Apesar de a amamentação exclusiva ser recomendada até seis meses, observamos uma contradição desta recomendação com as leis trabalhistas brasileiras, nas quais a mulher tem apenas 120 dias, ou melhor dizendo, quatro meses de licença maternidade. Este fato observado pelas falas é um dos fatores primordiais apontados pelas mães para a não-manutenção da amamentação. Outro aspecto a ser levado em consideração é que a lei prevê para as mães, a saída mais cedo ou a entrada mais tarde no trabalho, e ainda a exigência de creches no local de trabalho caso a firma empregue mais de 30 mulheres.

Na prática, esses direitos não vêm sendo usufruídos pelas mulheres, muitas das quais não os conhecem. Ainda com relação ao retorno do trabalho aponta-se que muitas mulheres desconhecem a prática da ordenha e da conservação do leite humano, como uma possibilidade de manutenção do aleitamento materno.

A categoria "provoca dor" emergiu somente no grupo Tr. As mulheres relatam dor física e insatisfação em dar o peito, principalmente nas primeiras mamadas (tal desconforto tendia a melhorar com o passar do tempo). Arantes ${ }^{10}$, ao estudar a amamentação, buscando compreender seus significados, identificou aspectos relativos a momentos negativos $\mathrm{e}$ desagradáveis vividos pelas mulheres, evidenciando uma visão diferente do que se vem apregoando de modo idealizado nos discursos oficiais em prol do aleitamento. Seguramente, um desses momentos citados pelo grupo $\mathrm{Tr}$ foi a questão da dor provocada pela pega incorreta do bebê ao seio materno, como as falas a seguir mostram:

Quando ela mamava era uma dor imensa, mas eu agüentava, tinha que agüentar a dor ( $\mathrm{M}^{13}$ - grupo $\left.\mathrm{Tr}\right)$.

Foi muito doloroso no começo porque rachou. Eu chorava junto com ela ( $\mathrm{M}^{11}$ - grupo $\mathrm{Tr}$ ).

Na categoria "não satisfaz, não sustenta, bebê chora muito", a evocação surgiu somente no grupo de mulheres Ntr. Esta categoria é pequena (5\%), refletindo sua pequena relevância para esse grupo estudado, neste momento, em especial nesta evocação. Pode-se observar na fala das entrevistadas uma correlação do choro do bebê com a suposta insuficiência do leite materno. Este fato pode demonstrar não somente a falta de vontade da mulher em querer amamentar, mas também seu desconhecimento em relação à suficiência do leite humano e aos mecanismos da produção do leite, e ainda o mito de que todo choro do bebê está relacionado à fome. É conhecido na literatura que, após o nascimento e até aproximadamente 5 a 6 meses de vida, o bebê chora muito devido a dores abdominais, ou quando se sente incomodado com algo. As falas a seguir ilustram estes pontos:

Ela mamava e eu sentia que ela ficava chorando com fome, parece que o meu leite não estava sustentando ( $\mathrm{M}^{14}$ - grupo Ntr).

Eu tinha a sensação de que ele chorava de fome. Acho que meu leite não estava sustentando ( $\mathrm{M}^{15}$ - grupo Ntr).

\section{Tirar do peito}

As respostas obtidas quanto ao indutor "tirar do peito" apresentado foram agrupadas em 4 categorias, que as sintetizam, apresentadas a seguir na Tabela 4.

\section{Tabela 4:}

Distribuição das associações à palavra tirar do peito

Resende - RJ, 2005

\begin{tabular}{l|c|c|c|c|c|c}
\hline \multirow{2}{*}{ CATEGORIAS } & \multicolumn{2}{|c|}{ Total } & \multicolumn{2}{c|}{$\begin{array}{c}\text { Grupo que } \\
\text { não trabalha } \\
\text { (Ntr) }\end{array}$} & \multicolumn{2}{c}{$\begin{array}{c}\text { Grupo que } \\
\text { trabalha fora } \\
(\text { Tr) }\end{array}$} \\
& \multicolumn{2}{|c|}{$\mathrm{n}=15$} \\
\hline & $f$ & $f \%$ & $f$ & $f \%$ & $f$ & $f \%$ \\
\cline { 2 - 7 } Filho doente & 22 & $48 \%$ & 13 & $69 \%$ & 09 & $33 \%$ \\
A criança vai sentir falta & 14 & $30 \%$ & 05 & $26 \%$ & 09 & $33 \%$ \\
A criança é que sabe. & 05 & $11 \%$ & 00 & $00 \%$ & 05 & $19 \%$ \\
Difícil e triste para a mãe & 05 & $11 \%$ & 01 & $05 \%$ & 04 & $15 \%$ \\
Total de evocações & 46 & $100 \%$ & 19 & $100 \%$ & 27 & $100 \%$ \\
\hline
\end{tabular}

Quando se fala em "tirar do peito", a categoria mais freqüente foi "filho doente" $(48 \%)$, seguida pela categoria "a criança vai sentir falta" (30\%), e finalmente "difícil e triste para a mãe" e "a criança que sabe", com $11 \%$ cada respectivamente.

A categoria "filho doente" emergiu em ambos os grupos, porém com maior freqüência no grupo Ntr (69\%). Aqui, mais uma vez, é verificada a relação da amamentação com a prevenção de doenças. As mães relatam que, ao largarem 0 peito, as crianças passam a correr mais riscos de adoecerem. Algumas falas das mães exemplificam esta relação:

Tirar do peito não é bom, se tirar a criança perde a proteção, fica mais doente $\left(\mathrm{M}^{16}\right.$ - grupo $\left.\mathrm{Tr}\right)$.

Acho que a criança deve ficar mais doente ( $\mathrm{M}^{17}$ - grupo Ntr).

Almeida ${ }^{11}$ relata que as mães verbalizam de forma simples $\mathrm{e}$ direta o que a ciência comprova por meio de complexas manobras e artifícios: Cada mamada é uma vacina, cada vez que ofereço o peito a meu filho; antes mesmo de alimentar eu o estou protegendo de doenças com o meu próprio leite. Aqui cabe destacar que, ao evitar que a criança seja privada do leite materno, ainda que 0 aleitamento não seja mais exclusivo, as mães estão desempenhando o papel de protetoras. Assim, a complementação alimentar do aleitamento não interfere com essa proteção.

A categoria "a criança vai sentir falta" teve mais expressão no grupo $\operatorname{Tr}(33 \%)$. No entanto, também aparece no grupo oposto $(26 \%)$. Percebe-se nas falas das entrevistadas, uma 
diferença em relação a essa categoria. No grupo Ntr, as mães fazem referência à falta do leite para a criança, principalmente pelo prejuízo nutricional. A representação de tirar o peito para essas mães ocorre em torno da proteção de doenças. Por outro lado, para as mães do grupo Tr, a representação de tirar do peito está mais voltada para questão do vínculo afetivo. Este fato pode ter ocorrido neste último grupo em função do tempo que as mães passam distantes de seus filhos devido ao trabalho.

Esta inferência pode também ser observada na categoria "difícil e triste para a mãe", que também esteve mais freqüente no grupo $\operatorname{Tr}(15 \%)$. As mulheres desse grupo expressam um sentimento de quebra do vínculo mãe-bebê devido ao afastamento pelo trabalho, o qual pode ser resgatado através do pouco tempo em que elas ainda amamentam seus bebês. Dessa forma, enxergam nessa ruptura um prejuízo para elas próprias, do ponto de vista de sua realização como mãe. Suas falas explicitam estes aspectos:

Deve ser triste. A gente acostuma e não faz bem. Eu acho que faz falta para a mãe e para o filho ( $\mathrm{M}^{1}$ - grupo $\mathrm{Tr}$ ).

É ruim, porque é muito gostoso amamentar, olhar no olhinho dele enquanto está mamando é muito gostoso ( $\mathrm{M}^{18}$ - grupo $\mathrm{Tr}$ ).

Finalmente, emergiu uma categoria evocada apenas no grupo $T r$, mesmo assim com uma freqüência relativamente baixa (19\%). Aqui, as mães expressam a importância que atribuem à autodeterminação da criança no sentido de regular 0 aleitamento. Winniccot ${ }^{12}$ refere que a amamentação deve ser dada somente quando o bebê quiser, e deve ser encerrada apenas quando ele deixar de querê-la. Neste sentido, muitos estudos têm procurado compreender o estabelecimento do vínculo mãe-bebê e a sua relação com a amamentação.

\section{Leite do peito}

As respostas obtidas quanto ao termo indutor "leite do peito" foram agrupadas em três categorias (Tabela 5).

\section{Tabela 5:}

Distribuição por percentual das associações à palavra leite do peito. Resende - RJ, 2005.

\begin{tabular}{l|c|c|c|c|c|c}
\hline \multirow{2}{*}{\multicolumn{1}{c|}{ CATEGORIAS }} & \multicolumn{2}{|c|}{ Total } & \multicolumn{2}{c|}{$\begin{array}{c}\text { Grupo que } \\
\text { não trabalha } \\
\text { (Ntr) }\end{array}$} & $\mathrm{n}=15$ & \multicolumn{2}{c}{$\begin{array}{c}\text { Grupo que } \\
\text { trabalha fora } \\
\text { (Tr) }\end{array}$} & $\mathrm{n}=15$ \\
\hline & $f$ & $f \%$ & $f$ & $f \%$ & $f$ & $f \%$ \\
\cline { 2 - 7 } Evita doenças, faz crescer & 62 & $77 \%$ & 30 & $72 \%$ & 32 & $82 \%$ \\
Fraco e não sustenta & 11 & $13 \%$ & 06 & $14 \%$ & 05 & $13 \%$ \\
Importante até 06 meses & 08 & $10 \%$ & 06 & $14 \%$ & 02 & $05 \%$ \\
Total de evocações & 81 & $100 \%$ & 42 & $100 \%$ & 39 & $100 \%$ \\
\hline
\end{tabular}

Quando se falou em "leite do peito", a categoria mais freqüente nas evocações foi "evita doenças, faz crescer" $(77 \%)$, seguida das categorias "fraco e não sustenta" (13\%) e "importante até seis meses" (10\%).

A categoria "evita doenças, faz crescer" aparece em ambos os grupos. As mães associam o leite materno à prevenção de doenças. Além do aspecto nutricional, elas encaram leite do peito um "remédio" capaz de proteger a criança de diversos males da infância e da vida adulta, conforme citado anteriormente. Como exemplos destacam-se as seguintes falas:

É bom para criança porque evita infecções, bactéria e é carinho ( $\mathrm{M}^{7}$ - grupo $\left.\mathrm{Ntr}\right)$.

Leite do peito é bom, para mim, é um remédio, é um sustento, é ótimo para ela ( $\mathrm{M}^{12}$ - grupo $\mathrm{Tr}$ ).

$\mathrm{Na}$ categoria "fraco e não sustenta", as evocações foram equivalentes, com $13 \%$, respectivamente para os grupos Ntr e Tr. Pode-se observar que, neste termo indutor - "leite do peito", esta categoria, diferentemente do termo indutor "dar só peito", aparece com uma freqüência maior e nos dois grupos, o que leva à reflexão de que este mito do "leite fraco" ainda é fortemente associado ao leite humano, mesmo nos dias atuais.

Essas afirmações provavelmente ocorreram devido à desinformação e à interpretação da aparência fina do leite materno, quando comparado às fórmulas lácteas engrossadas. 0 mito do leite fraco tem suas raízes no higienismo, quando ele foi utilizado para dar plausibilidade científica aos desvios do modelo estritamente biológico então em vigor. Posteriormente, foi ele utilizado como argumento para justificar a introdução precoce de alimentos lácteos artificiais na dieta do lactente, com estímulo da indústria alimentícia e pleno aval dos profissionais de saúde. Neste sentido, as falas das mães, apresentadas a seguir, expressam estes aspectos:

Eu acho que o leite do peito não enche muito a criança ( $\mathrm{M}^{1}$ - grupo Tr).

Para mim o meu leite não sustentava. Acho que o meu leite era fraco, ela chorava o dia todo ( $\mathrm{M}^{7}$ - grupo $\mathrm{Ntr}$ ).

A evocação da categoria "importante até seis meses" foi mais freqüente no grupo Ntr (10\%). As mães demonstraram certo conhecimento quanto à importância do leite materno e da duração do aleitamento até o sexto mês. No entanto, elas destacaram a importância da exclusividade e a continuidade até os dois anos de vida, como preconizado pela OMS. Esses fatores não apresentam relevância na representação da amamentação nesse grupo de mulheres.

Outro aspecto a ser destacado nesta categoria, que a diferencia da categoria "criança é que sabe", a qual emergiu do indutor no grupo oposto (grupo Tr), é que as mulheres do grupo Ntr não acreditam que a criança deva ter o papel de estabelecer o prazo de amamentação, mas sim que esse prazo é predeterminado até os seis meses de vida. As falas das mães mostram esta posição:
É bom para a criança, é o melhor leite para evitar doença. A criança precisa só do peito só até seis meses ( $\mathrm{M}^{17}$ - grupo Ntr).
Eu acho que é o melhor alimento. A criança quase não fica doente. Acho que é necessário até seis meses ( $\mathrm{M}^{4}$ - grupo Ntr).

\section{CONCLUSÃO}

Os dados da pesquisa mostram que, embora a maioria das mulheres de ambos os grupos estudados reconheça o valor da prática do aleitamento materno e das qualidades do leite 
humano, o mesmo reconhecimento não é dado à questão da exclusividade, nem tampouco ao tempo necessário do aleitamento exclusivo. As mulheres que não trabalhavam fora ancoraram a representação da amamentação no processo saúde-doença, utilizando o senso comum de que ter saúde é simplesmente ausência de doenças.

A representação da expressão "tirar do peito" diferiu entre os dois grupos, visto que o grupo de mulheres que não trabalhavam fora associou o leite à proteção de doenças, ao passo que o grupo de mulheres que trabalhavam fora expressou um sentimento de quebra de vínculo entre mãe e bebê. De modo interessante, a palavra indutora "dar só peito" esteve fortemente associada aos aspectos que denotam ser árduo e sofrimento, especialmente no primeiro grupo. Diferentes achados em ambos os grupos, Ntr e Tr, são explicados pela condição inerente à mulher-trabalhadora que necessita de

\section{Referências}

1. Araújo MFM. Situação e perspectivas do aleitamento materno no Brasil. In: Carvalho MR, Tamez RN. Amamentação: bases científicas para a prática profissional. Rio de Janeiro(RJ): Guanabara Koogan; 2002.

2. Jodelet D. Lês represéntations sociales. Paris(FR): Puf; 1989.

3. Rea MF et al. Possibilidades e limites da amamentação entre mulheres trabalhadoras formais. Rev Saúde Pública 1997; 31(2): 149-56.

4. Moscovici S. Representações sociais: investigações em psicologia social. Petrópolis( RJ): Vozes; 2003.

5. Bardin L. Análise de conteúdo. Lisboa(PT): Ed 70; 1977. 226p.

6. Queiroz ABA, et al. Desvendando a situação de infertilidade e seus reflexos no gênero feminino através do programa informatizadoAlceste. Esc Anna Nery Rev Enferm 2003 dez; 7 (3): 388-97.

7. Spíndola T. Trabalho feminino...uma só mulher! Ambivalências do cotidiano.[tese de doutorado]. Escola de Enfermagem Anna Nery/ UFRJ; 2002.

8. Chodorow N. Psicanálise da maternidade: uma crítica a Freud a partir da mulher. Rio de Janeiro(RJ): Rosa dos Tempos; 1990.

9. Badinter E. Um amor conquistado: o mito do amor materno. Rio de Janeiro(RJ): Nova Fronteira; 1985.

10. Arantes CIS. Amamentação: visão das mulheres que amamentam. J Pediatr 1995; 71(4): 195-202.

11. Almeida JAG, et al. Amamentação: um híbrido natureza-cultura. Rev Latino-am Enfermagem 1998; 6 (3): 71-75.

12. Winnicott DW. Os bebês e suas mães. São Paulo(SP): Martins Fontes, 1994. dividir seu tempo entre a jornada de trabalho fora do lar, os afazeres domésticos e o cuidado da família. Compreender as particularidades das condições das mães no período do aleitamento, atentando para essas diferenças e tentando auxiliá-las no enfrentamento das dificuldades que ocorrem durante esse período tão crítico, é tarefa da equipe de saúde, e sobretudo da equipe de enfermagem.

Concluindo, o estudo de RS constitui uma ferramenta útil e reveladora para compreender aspectos psicossociais do processo de amamentação e de sua interrupção prematura. Esses aspectos devem ser levados em consideração pelos profissionais de saúde e enfermagem que lidam com gestantes, puérperas e lactentes em fase de aleitamento, bem como na elaboração de políticas públicas mais eficazes para fortalecer a prática assistencial em saúde da amamentação em nosso meio, muitas vezes incompleta e/ou insuficiente.

\section{Notas}

a Trabalho premiado em $2^{\circ}$ lugar pelo Núcleo de Pesquisa em Enfermagem na Saúde da Mulher, do Departamento de Enfermagem Materno-Infantil da Escola de Enfermagem Anna Nery/Universidade Federal do Rio de Janeiro, por ocasião da realização do $13^{\circ}$ Pesquisando em Enfermagem, em maio de 2006.

\section{Sobre as Autoras}

\section{Cácia Mônica Osório}

Enfermeira. Mestranda da Escola de Enfermagem Anna Nery / UFRJ. E-mail: caciamosorio@oi.com.br.

\section{Ana Beatriz Azevedo Queiroz}

Professora Adjunta do Departamento de Enfermagem MaternoInfantil da Escola de Enfermagem Anna Nery / Universidade Federal do Rio de Janeiro. 